\title{
Remembering Mass: Response to YANG Xiaomei
}

\author{
Chad Hansen
}

Published online: 5 October 2011

(C) The Author(s) 2011. This article is published with open access at Springerlink.com

I am honored that Professor Yang has lavished such attention on my decades-old argument and I am pleased to respond. I've changed. Decades ago when the argument was fresh, I resisted answering critics who misconstrued my argument. Instead, I had a series of long conversations with them, including but not limited to those to whom Professor Yang appeals. I remember the conversations fondly because they started many life-long friendships-particularly with Christoff Harbsmeier, BAO Zhi Ming, Henry Rosemont, Roger Ames, and Angus Graham.

All the conversations are rich in my memory but the pivotal one for my current change in strategy was with Christoff (inevitably, over a beer-a tradition we both cherish and repeat at every opportunity). Christoff and I met after he generously invited me to discuss drafts of his article criticizing my "mass noun hypothesis." I pointed out that he had formulated and criticized a Whorfian version of what was a Quinian (and Wittgensteinian) argument. Although I thought his attack on Whorf weak, I ignored the issue since, for me, he was attacking a straw man, i.e., his own mass noun hypothesis. He responded that if he had misstated my argument, I should respond to him in detail in print otherwise his presentation of my argument "would stand." I argued that responding would simply consist of my repeating myself; that philosophers and other academics could (and would) read his article and my book for themselves and would see how the two were different. After multiple beers and lengthy vigorous discussion we parted friends agreeing to disagree.

In my youth, I cherished more faith in the objectivity of philosophy and the power of reason. Age has made me realistic about the politics of academic discourse. Christoff and I reprised the moment in Amsterdam last November (over beer, of course) and I admitted to Christoff that he had won the bet. Almost all published comments since his

Chad Hansen $(\bowtie)$

Philosophy Dept., School of Humanities, University of Hong Kong, Pokfulam, Hong Kong e-mail: chadzi@gmail.com 
have credited me, as Professor Yang does here, with Christoff's Whorfian version of the "mass noun hypothesis" rather than my own. Chastened now by the operation of quorum sensing in academia, I have begun to publish my objections to this distortion of my argument. In the meantime, I have come to understand better the theory of meaning and how radical translation works, so while the argument structure is the same, my ability to explain it has changed so I won't merely be repeating it.

My argument started from Quine's skepticism about meaning and his radical translation argument for dealing with that skepticism. Let us call mine the MassQuine and Christoff's the Mass-Whorf hypothesis-Professor Yang's formulation of it is typical. The central difference is that the mass-Whorf, empirical linguist takes meaning facts as data to be explained causally by grammar. Mine was not a linguistic argument but an argument about the ancient Chinese theories of language that lay behind the dispute between the Mohists and Gongsun Long about "White Horse." I did speculate about a linguistic matter that may have distracted readers. I noted that Pre-Han grammar was not a mass noun grammar because it directly modified nouns with numbers. So I called it a hybrid noun structure, and noting that historical linguists claimed that the regularization of sortal use dates from the Han reform, I speculated that it may have been motivated by the same background theory ming 名 (names). My argument, however, was solely about reconstructing that background theory from the texts using Quine's Radical Translation argument form. The goal of the theory was explaining the White Horse dispute, not that speculative by-product.

Quine was skeptical of meaning. He argued that meaning defied non-circular analysis and used radical translation to illustrate what empirical verification of meaning claims would amount to. I wanted to argue there was a correct way to interpret the phrase and my argument did rely on natural causation. Besides reversing the argument, the Mass-Whorf hypothesis uses causal necessity/sufficiency where the Mass-Quine relied on only causal possibility/probability. Quine argued that radical translation projects lacked any unique solution and concluded that meaning claims are not empirically verifiable. From this attack on the "two dogmas" of empiricism, he concluded that there could be no fact of the matter about what a word or expression means. That was the argument I attempted to answer-focused on the White-Horse paradox of bai ma fei ma 白馬非馬. I had thought that GonGSUN Long must somehow be confusing subclass and class membership relations.

Quine's pivotal claim that inspired my line of reasoning was that time-slices, instantiations, compositions, and masses and many other interpretations of ordinary nouns like "rabbit" were empirically compatible with any language in radical translation. Quine's gavagai discussion, not the grammar of Chinese, triggered my consideration of a mass-like solution. The philosophical problem that gripped me was how to construct an interpretive argument for understanding the White Horse puzzle that could evade Quine's meaning skepticism. To understand the role of causation, one must first feel the grip of Quine's philosophical puzzle, be skeptical of the very meaning facts that constitute the empirical linguist's data.

I wondered how we could prove that baima 白馬 in baima fei ma 白馬非馬 had any definitive meaning. One of the proposed theories was that it means "white horseness," and another "a white horse" - both giving the meaning in English. The consensus then was it meant both depending on which one made each claim true. 
Chinese words, I learned in Sinology, "have lots of meanings." Quine argued for an analysis of claims about inter-linguistic meaning. He proposed radical translation as an indirect way of verifying these claims. Instead of appealing to the meaning to justify a translation, Quine suggested, we must reverse the order of justification. If we can justify a translation as being correct without relying on a meaning premise, then we can justify a conclusion that they share an inter-linguistic meaning-even absent an analysis of "meaning." We refer to the sentences of the object language and give their meaning indirectly via their "correct" translation into a meta-language whose meaning we do understand.

We show a translation is correct indirectly by applying a translation manual to strings of the object language. So our task becomes justifying a choice between translation manuals. Quine relied on the systematic relation of meaning and belief in this justification. The rival "translation manuals" play roles analogous to rival explanatory theories except they interpret rather than causally explain the beliefs. They semantically assign meanings to strings to yield the beliefs we use to justify the manuals that generate them from assertions in the texts. The manuals consist of entries for the lexical items (Chinese characters) and a semantic syntax-a systematic function from grammatical structures and the lexical items that yields an English sentence for each possible sentence of the target language.

Quine argued for starting this project using "stimulus meaning" as the empirical test. In effect, we take an empirical happening in the world of speakers as causing them to make or assent to an utterance. The correct translation manual then assigns English expressions of a belief (assertion) that would be similarly stimulated-e.g. a rabbit's jerkily dashing across the field. However, Quine noted, the very same stimulus could generate the belief that there is rabbit-stuff, an instance of rabbithood, or a collection of rabbit-parts before us. All are equally well-grounded in the empirical situation - hence his indeterminacy of translation. So, far from solving it, Quine suggested that the problem defied solution. There was no way empirically to verify that one or the other of the translations was correct, hence no determinate fact about inter-linguistic meaning.

I was trying to work out how we could narrow the range of preferred translation manuals for Classical Chinese. One clue was in Quine and originated with Chomsky (as I had learned from Henry Rosemont) — syntax did matter. The meaning of a sentence had to be a product of the application of learnable grammatical rules to a finite and determinate list of lexical items. Native speakers' competence should enable them to understand indefinitely many novel sentences by understanding the concepts + the grammar. The meaning of a sentence should be accessible to them as a reliable consequence of putting those concepts in that syntactical structure. Only what that grammar could express with those concepts could be a meaning of a sentence of Wenyan. Notice that this point is not limited to Chomsky's natural languages - the same is true of logic, mathematics and etc. Probably the reader has never seen the number 580,752,989, but anyone who knows arithmetic conventions can understand it by understanding 10 digits and the rules for construction using base 10 .

Still, grammar does not have any direct causal relation to the content of concepts. Causal probability enters the account in a much different role-i.e., as when reasons are causes. Still, the semantic syntax insight is fundamental and often ignored. To 
repeat, what a sentence can mean is a function of a learnable grammar and the range of concepts and their learnable contents. Conceptual contents play the roles that fill empty slots in the grammar. Baima 白馬, whatever it means, must function as an ordered pair of lexical items filling the empty slot in the structure “_fei ma 非馬."

Further, the lexical entry should not consist of a long disjunction (a free choice) of English translations unless they share a meaning. The native community is able to compose and derive the meaning of complex sentences from the lexical content, the grammar and discourse context. They do not walk around with Chinese-English dictionaries or the inner thoughts of modern interpreters in their heads. This I joked was the "English is the only real language" fallacy and hence rejected the familiar list of English equivalents - that ma 馬 can as necessary mean each of "horseness," "a horse," "the species," "the collection," etc. A definitive learnable lexical meaning should combine grammatically in a reliable grammatical way to yield a single sentence meaning for the community. I argued that "horse-stuff" did this best.

Still I needed an argument for horse-stuff as the single entry in the translation manual. The crucial thing Quine had noticed was a correlation of meaning and belief. We can assign anything we want as the meaning entry as long as we were willing to ascribe the linked beliefs to the community (and vice versa). So Quine's method opened up the possibility, exploited first by Davidson, that we select the translation manual that ascribed true beliefs to the community. That is, when we have translated all their expressions and assents into English, the English result should be that which produces a maximally true set.

The beliefs, again, had to be generated by a perfectly general syntax and a finite cluster of lexical contents (English translations of terms). In Quine's terms, the result had to be holistic - we could not achieve it as above. Quine's indeterminacy lay in the choice of the single consistent meaning to assign the term not the freedom to make it what we like on an ad hoc basis. "Horse-stuff" did make GongSun Long's head sentence false but many others from the Mohist true. That approach makes the project look too arbitrary, however, counting how many assertions of a particular school survive to the present. Was it true until scholars learned how to read the Mohist Canon, and then suddenly became false? The correct meaning should not be a function of such later historical developments.

Davidson's interpretive charity had several other theoretical drawbacks. One was that the holism, while blocking ad hoc meaning variation, did not remove the indeterminacy. There being a rabbit entails that there being a member of the species, some rabbit-stuff, a sequence of time-slices of rabbit etc. Furthermore, truth charity deals with theoretical beliefs in an improbable way. Astronomy now finds evidence of up to 10,000 super galaxy-clusters - the largest composite "things" making up the universe. We shouldn't take that to justify understanding $w u$ 物 as “super galaxycluster." The principle of charity, so understood, biases interpretation toward agreement with us - "to understand is to agree." It should be theoretically possible both to understand and disagree with other linguistic communities.

Quine's proposal was not truth but "stimulus meaning." The truth that a rabbit was there did not explain the belief. That the speakers were ordinary humans with eyes that worked like those of the anthropologist-linguist. That they could see and, like us, would have their attention drawn to a rabbit's scurrying around nearby. Quine had noticed that the counterpart to "stimulus conditions" for theoretical beliefs 
like those of modern science, required access via shared theories, concepts, practices, and methods of explaining and justifying things. The truth by itself explains nothing without a mode of causal access. This is where causation enters semantic theory and the insight applies to religious, ethical, and metaphysical beliefs as it does to theoretical science. Missionary translators who sought the Chinese word for "God" tended to justify their practice by appeal to "natural religion." The rational mind naturally inclines to creationist monotheism. Not the truth of God's existence, but the hypothesis that rational beings had a natural mode of access to that truth justified treating 天 as 'God.' The mode of causal access here is reasoning. Reasoning causes beliefs $\mathrm{A}$ and $\mathrm{B}$ to generate $\mathrm{C}$.

Notoriously, furthermore, human philosophical reasoning can start from what seem like self-evident principles that turn out to be wrong. Some errors (fallacies) of inference are common. These can explain what I called "understandable error" and taken together with my analysis of the Mohist discussion of niu ma 牛馬 (ox-horse), I proposed such a rational-causal explanation of bai ma fei ma 白馬非馬 that concluded it was in error. Making it false would have counted against my translation manual had I relied on the metaphysical principle of charity.

This way of slicing the Quinian knot for bai ma 白馬 was then being formulated as Grandy's "Principle of Humanity." It relies on psychological similarity to us but not agreement in beliefs. The patterns of relationship among beliefs, desires, motivations are recognizably human. We comparatively prefer the translation manual for which we can provide the more naturalistically plausible explanation given the cognitive situation. We can plausibly attribute a set of beliefs to a community when we can imagine ourselves drawing the inferences they draw-given their presuppositions, language, access to information, traditions etc. It is the causation we recognize in ourselves when we come to believe something based on new evidence, deeper explanation, longer reflection, theorizing - any causally natural human process of modifying and acquiring beliefs.

This is the conception of "explain" that is relevant to my project. The "causes" of beliefs are typically other beliefs, and we are humans reasoning about things. Beliefs can be caused by being taught by opinion leaders, transmitted via trade, revealed in dreams, etc. Where we find philosophy, we should appreciate that beliefs can also be produced (caused) by inference from other beliefs - including abduction, philosophical reflection, and reduction. Philosophical theorizing is caused in that sense. "Horse-stuff" works because I can use it, together with a causally plausible background theory of language, to explain both the Mohists' true claims about bai $m a$ 白馬 and GoNGSUN Long's false ones.

I realized, therefore, that I could answer Quine if I did more than what Dr. Yang acknowledges, at the end, my theory does-provide a plausible explanation of the white horse dialogue. Like truth, unfortunately, there are many ways to explain. The naturalistic causal principle of humanity does not leave me free to propose just any combination of background beliefs and assumptions. The principle of humanity avoids the indeterminacy because it requires that set of background beliefs postulated be more naturalistically plausible than the rival generated to support an alternative translation manual. So the measure of relative causal probability yields a definitive preference between any two rival hypotheses. I strive to show that access to those assumptions themselves arises from humanly plausible lines of reasoning for 
that linguistic community given their epistemic circumstances. The explanatory hypotheses used in selecting from the rival packages of beliefs, should both explain and be explained. However, the explanation uses causal probability, not necessity, and Plato's theory of forms, as Professor Yang notices, can be explained by the combination of a towering intellect, an intellectual puzzle, a set of conceptual and philosophical tools, and so on. No one would claim the grammar of Greek was a necessary and sufficient condition of Platonism, nor do I claim the counterpart for the Mohist theory of ming 名 (names).

For the record, as with Christoff's arguments, I doubt the attack on Whorfianism is sound, but that matter belongs to empirical linguistics and the neuro-psychology of language. It is irrelevant to my argument. Like my friend Christoff, Professor Yang may insist that contrary to my own recollection and protestations, I was indeed motivated as they insist by their Mass-Whorf argument. I cannot force them to accept my own recollections about my argument, but I hereby invoke first person authority.

Open Access This article is distributed under the terms of the Creative Commons Attribution Noncommercial License which permits any noncommercial use, distribution, and reproduction in any medium, provided the original author(s) and source are credited. 